\title{
A Child Presented with Clitoromegaly in Context with Neurofibromatosis Type 1
}

Zeindine Sirena $^{1 *}$ and Al Ebrahem Asad ${ }^{2}$

${ }^{1}$ Faculty of Medicine, Damascus, Syria

${ }^{2}$ Department of Pediatrics University Hospital, Damascus, Syria

*Corresponding author: Zeindine Sirena, Faculty of Medicine, Damascus, Syria

Received: December 15, 2020; Accepted: January 12, 2021; Published: January 19, 2021

\begin{abstract}
Neurofibromatosis type 1, also called Von Recklinghausen Disease is a genetic disorder characterized by the development of multiple benign tumors affecting the skin and nervous system. It is a genetic disease with a prevalence of one case in 3000 births. The cause of VRD is a genetic mutation [1-4]. In half of all cases of NF1, the faulty gene is passed from a parent to their child. Clitoromegaly presenting in childhood can be congenital or acquired. Nonhormonal causes like NF1, epidermoid cysts, tumor syndromes have been reported [5]. Clitoris enlargement is a frequently seen congenital malformation, but acquired clitoral enlargement is rarely detected.
\end{abstract}

While most cases of VRD are the result of a genetic mutation in the neurofibromin gene, there are also acquired cases due to spontaneous mutations [4]. The pathological alterations behind it begin in the embryonic period, prior to differentiation of the neural crest. We report a case of 6.5 year old - female admitted for clitoromegaly and an apparent deformity of the genital organs.

The girl has been diagnosed with clitoromegaly in the context of NF1 Disease. This patient was successfully treated by clitoroplasty. The biopsied clitoral tissue was sent to pathology and revealed plexiform neurofibroma. Child

Keywords: NF1; Von Recklinghausen Disease; Clitoromegaly; Clitoroplasty;

mentioned a case of Von Recklinghausen in a 3rd degree relative.

The spiritual-kinesthetic development is normal Birth conditions are normal.

Weight $20 \mathrm{~kg}$ (0 standard deviation).

Height $120.5 \mathrm{~cm}$ (0 standard deviation).

Height for age growth is within normal.

Otherwise, the child girl is in good health.

\section{Ophthalmological Status}

Ophthalmic examination with slit lamp is normal.

Visual examination is normal with visual ability $10 / 10$ in both sides with absence of Lisch nodules post Slit-lamp examination.

Physical examination.

Dermatological status:

8-9 Cafe au lait patches (size 1-2 cm) on trunk, multiple freckles on axillary, trunk and inguinal region.

No symptoms of hyperandrogenism.

The bone age matches the clinical one.

Lab and Imaging Studies, Histological Findings and Consultations

The standard laboratory tests values were in the normal range with the only exception of high levels of DHEA $(52.91 \mu \mathrm{g} / \mathrm{dl})$.

And when asking the mother about familial diseases she 


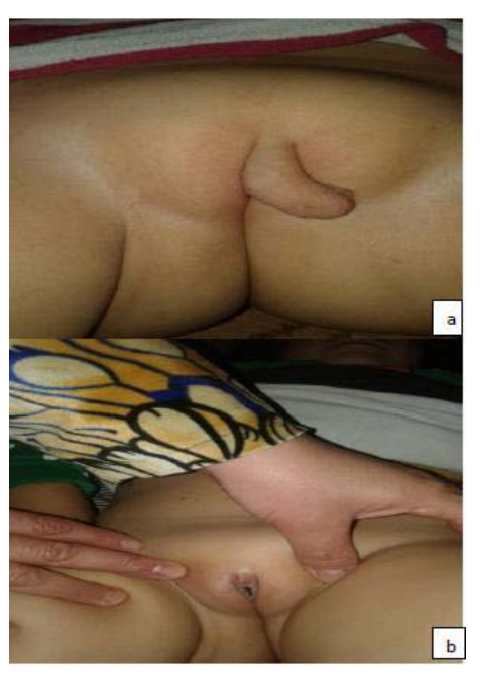

Figure 1: (a) clitoromegaly before surgery (b) after clitoroplasty.

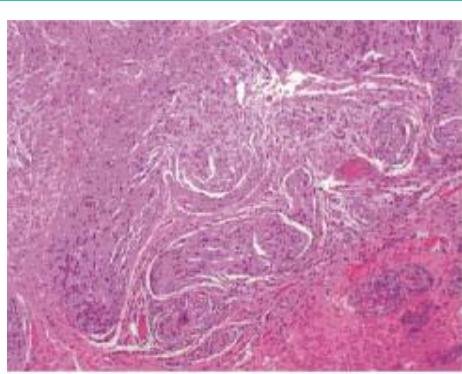

Figure 2: Plexiform neurofibroma.

Hand X-Ray photography was within the normal too.

Abdomenopelvic ultrasound was done and showed normal internal genital organs.

The histological result revealed plexiform neurofibroma.

\section{Discussion}

Von Rcklinghausen disease is a multisystem disorder affecting approximately 1 in 3000 people in South East Wales. The symptoms [4] usually appear in childhood and progress with time, and the criteria of VRD are Table 1.

- Family history of NF.

- 6 or more cafe- au-lait patches which are hyper pigmented lesions in different sizes and shapes mainly on trunk.

- 2 or more Freckles in the axillary or inguinal area.

- Lisch nodules which are hamartomas of the iris and they are best diagnosed with slit-lamp examination.

- Cutaneous Neurofibromas that may not appear till puberty and increase in number and size with age.

- Plexiform neurofibromas which are tumors affecting the nerving bundles.

- $\quad$ Optic nerve tumors that may affect vision.
Neurofibromatosis type 1 represents a major risk factor for development of malignancy, particularly malignant peripheral nerve sheath tumors, optic gliomas, and leukemias [7].

Tumors can be treated by several methods, including: [4]

- Laparoscopic removal of cancerous tumors.

- $\quad$ Surgery for removal of tumors affecting the nerves.

- $\quad$ Radiation therapy.

- Chemotherapy.

Overall, prognosis is good but significant morbidity is common [3].

In our case, the patient complained of clitoromegaly since birth with gradual enlargement with years and gradual appearance of multiple cafe-au-lait patches and multiple freckles on trunk, and a positive family history of NF1.

The patient was successfully underwent clitoroplasty by preserving the glans of the clitoris and neurovascular bundles [1], and the excision tissue was sent to pathology.

She was followed up after the operation; there was no early or late post-operative complication.

\section{Conclusion}

NF1 is a multisystem disorder requiring management by multiple disciplines, often coordinated through a primary care physician or a geneticist [7].

The goal of clitoroplasty is to reduce the size of the genital tubercle to give a feminine appearance without compromising future sexual function [2].

After reviewing this case, we recommend that the management of a clitoral neurofibroma consists of surgical excision with all attempts to preserve the clitoris and its adjacent neurovascular structures without compromising future sexual function [1,8-11].

\section{Acknowledgement}

I would like to thank Professor Asad al Ebrahem for his help and support throughout this work.

\section{Statement of Ethics}

Informed consent was taken for this research. Our study ethical aspects were reviewed and approved by Damascus University, Deanship, Damascus, Syria.

\section{References}

1. Bilommi RD. Clitoroplasty in neurofibromatosis presenting as clitoromegaly. J. of Pediatric surgery case reports 2015 Mar Neha R.M, Earl Y.C. Clitoroplasty. ELSEVIER J. 2018.

2. https://www.sciencedirect.com/topics/medicine-and-dentistry/clitoroplasty

3. Pr Eric Legius. Neurofibromatosis type 1. Orpha net Report Series. July 20.

4. https://www.orpha.net/consor/cgibin/Disease_Search.php?Ing=EN\&data_ id=185\&Disease_Disease_Search

5. Steve K. Von Recklinghausen's Disease (Neurofibromatosis 1) Healthline. 2017. 
6. https://www.healthline.com/health/neurofibromatosis-1\#TOC_TITLE_HDR_1

7. Meenal G, Vincent H, Abhishek S, Duong Tu, Yemi AF and Lefkothea PK. Persistent progressive clitoromegaly is not always hormonal. Oxford academic J. 2020

8. https://academic.oup.com/jes/article/4/Supplement_1/MON-064/5833704
9. Neurofibromatosis type 1. Rook medical textbook of dermatology. 2016.

10. https://www.rooksdermatology.com/manual/c80-sec-0007

11. Chouaib Sayah, Mahmoud Benmahmoud, Smain Ait Yahia and Zineddine Soualili. Neurofibromatosis Type 1 (NF1): Case Report and Review of literature. 2016 